\section{Imagery-mediated habituation of the orienting reflex*}

\author{
R. M. YAREMKO, BRADLEY B. GLANVILLE†, and BRUCE T. LECKART \\ San Diego State College, San Diego, Calif. 92115
}

The effect of repeatedly imagining a stimulus on later OR habituation to the real event was studied. Groups of college Ss imagined the occurrence of either a light or a tone for 10 trials. A third group received $10500-\mathrm{Hz}$ tones and a fourth group received no stimulation. All Ss then received 10 habituation trials to the $500-\mathrm{Hz}$ tone. Ss who had imagined tones showed significantly greater habituation of the GSR component of the OR than Ss imagining a light or receiving no stimulation. This group was not significantly different from Ss who had received real tones prior to the habituation stimuli. The results suggest that the imagery process aided in the formation of a Sokolovian neuronal model which accelerated habituation. The results further suggest that OR habituation may be a component in various desensitization therapies which employ imagery techniques.

The recent experimental literature reflects an increasing interest in habituation of the orienting reflex (OR). No doubt, this is due in part to the re-emergence of attention as an investigable construct. In turn, OR phenomena promise to serve as a molecular substrate for this class of behaviors (the "conditioned reflex" of attention?) and certainly provide an eminent operational definition of reflexively based investigatory behavior.

The inspiration for a great deal of OR research has been Sokolov's (1963) theory of OR habituation. Sokolov proposes that the diminishing responsivity to repetitious stimulation is the result of active inhibition of the OR by a "neuronal model" of the stimulus formed somewhere in the nervous system. This neuronal model preserves all dimensions of the stimulus (e.g., frequency, intensity, duration, etc.), and each occurrence of a redundant event increases the precision of the model. With increasing precision, its capacity to act as a selective filter is enhanced; the "modeled" stimulus is blocked, while discordant stimuli are still capable of triggering effector organs. Thus, generalization of $\mathrm{OR}$ inhibition is a function of the amount of disparity, along one or more dimensions, between a novel stimulus and an already-habituated-to stimulus.

Investigations of $\mathrm{OR}$ habituation

* Based on an MA thesis by the second author. This research was supported by $S$ an Diego State College Grants 221-209-985 and 233-005-998 to the first author. Address requests for reprints to $R$. M. Yaremko, Department of Psychology, San Diego State College, San Diego, Calif. 92115 . Portions of this report were presented at the Psychonomic Society Convention, St. Lovis, November 11-13, 1971.

+ Now at Michigan State University, East Lansing, Mich. 48823. and generalization of inhibition generally corroborate Sokolov's contentions. Zimny \& Schwabe (1966) measured GSR amplitudes to changes in tone frequency. Test tones of either 1,000 or $4,000 \mathrm{~Hz}$ were presented after habituation trials to a $500-\mathrm{Hz}$ tone. Somewhat larger ORs were evoked by the $4,000-\mathrm{Hz}$ tone, and this stimulus produced significantly greater resistance to rehabituation than did the $1,000-\mathrm{Hz}$ test tone.

Similarly, Corman (1967) presented Ss with test tones of $670,1,000$, 1,400 , or $1,850 \mathrm{~Hz}$ after habituation to a $670-$ or $1,850-\mathrm{Hz}$ tone. Amplitude of the GSR to test tones was a function of the degree of dissimilarity to the habituation stimulus regardless of the direction of that discrepancy. This relationship was replicated by Yaremko (1969) using (factorially) small and large, positive and negative changes in ambient room illumination.

Other recent studies provide data which extend this phenomenon from simple physical stimulus manipulations to higher order "conceptual" dimensions. Unger (1964) and Zimny, Pawlick, \& Saur (1969) demonstrated OR habituation to numeric stimuli presented in predictable sequences (e.g., 1, 2, 3, 4, ..., etc.), and. OR dishabituation to an out-of-sequence test number. Yaremko, Blair, \& Leckart (1970) and Yaremko (1971) showed that varying direction and amount of change of a discrepant test numeral produced OR dishabituation relationships comparable to those obtained with lights and tones.

Habituation in these experiments is of course, studied by actual presentation of the physical stimulus. One parameter almost entirely ignored by those engaged in basic OR research "'imaginal" stimuli. However, considerable clinical research has been is the "dimension" of real vs so-called devoted to physiological response decrements (habituation or extinction) as a function of vicarious or imaginal stimulus experience, the majority of these inspired by Wolpe's systematic desensitization therapy by reciprocal inhibition (Wolpe, 1958; Wolpe \& Lazarus, 1966). While the stimuli employed in desensitization research are nonneutral, typically fear-arousing, and would likely produce behaviors labeled "defensive reflexes" (DRs) by students of the OR (e.g., Sokolov, 1963), the procedures and outcomes of desensitization research raise some interesting questions for OR theory.

Apropos this point, Lader \& Mathews (1968) speculate that the therapeutic effect of imagining a fear-arousing stimulus stems at least partly from simple habituation to various components of the stimulus and not necessarily entirely to counterconditioning of relaxation behaviors. Adopting Sokolov's distinction between ORs and DRs, this would suggest that $O R$ habituation may be an important, perhaps necessary, component process in systematic desensitization. Accordingly, investigation of $O R$ habituation within the imagery paradigm would seem to be of paramount importance, not only to a clearer understanding of the processes underlying desensitization, but also as a potential contribution to the basic OR literature.

Further, extrapolations from Sokolov's theory would allow the prediction that imagining some (especially neutral) stimulus should enhance speed of habituation to that stimulus when the real event occurs. That is, repeatedly imagining a stimulus should initiate the formation of a neuronal model of the stimulus. Refinement of the model should then occur more rapidly when the stimulus is actually presented.

Some recent research (e.g., Maltzman \& Raskin, 1965; Kohlenberg, 1970; Cohen \& Johnson, 1971), however, has questioned whether OR magnitude and resistance to habituation may be enhanced by operations which increase the signal value of the stimulus. For example, Kohlenberg (1970) instructed Ss to ignore one of three tonal stimuli. The larger GSR amplitudes recorded for the "ignored" stimulus were interpreted as indicating that the instructions increased the signal value of the stimulus and that this effect outweighed the effects of task demand characteristics. Harvey \& Wickens (1971), in a study of the effects of instructions on classical GSR conditioning, present further evidence of signal value effects. This position would suggest that repeatedly 
imagining some neutral stimulus on demand from $E$ would likely increase the signal value of that stimulus.

The present experiment was designed to test the alternative hypotheses that prior imaginal experience with a neutral stimulus (tone) would (1) accelerate habituation of the GSR-OR during encounters with the real stimulus, or (2) result in increased resistance to habituation, presumably because of the increase in signal value brought on by repeatedly imagining the stimulus.

SUBJECTS AND APPARATUS

Data were obtained from 13 male and 35 female introductory psychology students at San Diego State College. The $\mathrm{Ss}$ volunteered to satisfy a course requirement. The $S$ sat in a darkened IAC Model 401-A audiometric chamber containing a cushioned chair. A $2.5-\mathrm{cm}$-diam white light was located about $30 \mathrm{~cm}$ in front of $\mathrm{S}$. A Heathkit audiogenerator produced $500-\mathrm{Hz}$ tones delivered through Electronic Futures earphones at $60 \mathrm{~dB}$ (re: .0002 dyne $/ \mathrm{cm}^{2}$ ). The GSR was picked up as a dc resistance change from S's left palm and forearm by zinc-zinc sulfate electrodes in Lucite cups filled with Redux electrode jelly. Responses were amplified and recorded by a Grass Model 5-D polygraph containing a Grass 5P1 dc preamplifier. Paper speed was $1.5 \mathrm{~mm} / \mathrm{sec}$.

\section{DESIGN AND PROCEDURE}

On arrival, each $\mathrm{S}$ was assigned randomly to one of four conditions: a group which would imagine the occurrence of a light (Group IL), imagine tones (Group IT), receive real tones (Group RT), or receive no stimulation (Group NS). Each group had $n$ Ss before any group had $n+1$ Ss. The $S$ was told informally that the experiment was designed to study basic physiological responses to simple visual and auditory stimuli and that he was to remain alert and avoid excessive movement. He was then told that $\mathbf{E}$ would present a (model) tone and light. The tone-light sequence was reversed for half the $S s$ in each group, and the interstimulus interval was approximately 5 sec. Following presentation of the model stimuli, Ss in Groups IL and IT were requested to "mentally reproduce" the appropriate stimulus on command from $E$ (the word "imagine" delivered through an intercom by $E$ ). Ten such requests were delivered. The Ss in Group RT were given 10 tone presentations, while Ss in Group NS received no stimulation. In the final phase, all Ss then received 10 habituation trials to the tone. The intertrial interval varied randomly between 30 and $60 \mathrm{sec}$, with a mean of $45 \mathrm{sec}$ for all stimulus events during all phases of the experiment. Tone and light durations were $5.0 \mathrm{sec}$.

\section{RESULTS}

The ORs to the 10 tones presented in the final phase were measured. An OR was defined as the first GSR to occur within $1.4 \mathrm{sec}$ following stimulus onset. The GSR was transformed into $\log \Delta \mathrm{C}$ in micromhos. Habituation was assessed by (1) the number of trials needed to reach a criterion of one zero amplitude response, and (2) mean GSR amplitudes for blocks of two consecutive trials.

Trials to criterion data showed that Group NS was the most responsive $(\overline{\mathrm{X}}=8.50)$, followed by Group IL $(\overline{\mathrm{X}}=8.33)$, Group IT $(\overline{\mathrm{X}}=5.50)$, and Group RT $(\overline{\mathrm{X}}=3.17)$. Analysis of these data showed significant differences among the four groups, $\mathrm{F}(3,44)=6.85, \quad \mathrm{p}<.001$. Duncan's multiple range tests revealed that Group RT differed from Group NS and Group IL $(p<.001$ for each $)$. Group IT differed from Group NS and Group IL ( $p<.05$ for each) but was not significantly different from Group RT.

For GSR amplitude data, performance corresponded to that evidenced by the trials to criterion measure, with the exception that Group IL had slightly larger amplitudes than Group NS.

Analysis of variance indicated that the overall differences among groups a p proach ed significance, $F(3,44)=2.28, \quad p<.10$. The trials effect showed that significant habituation occurred among these groups, $F(4,176)=11.16, \quad \mathrm{p}<.001$, but the Groups by Trials interaction only approached significance, $F(12,176)=1.35, p<.10$. Hartley's F-max test indicated significant heterogeneity of variance for this response measure, $F(4,11)=8.69$, $\mathrm{p}<.001$, with Groups IL and RT being most discrepant.

\section{DISCUSSION}

On balance, these results are consistent with the hypothesis derived from Sokolov's neuronal model theory. The Ss who imagined tones prior to habituation evidenced substantially lower levels of responding during the habituation phase than all other Ss except those in the RT condition. Even here, Groups IT and RT did not differ significantly. The fact that Groups IL and NS did not differ significantly does not support the interpretation that the imagery task itself or the vocal stimulation provided by the imagery instructions contributed to the accelerated habituation in Ss imagining tones. Rather, the type of stimulation imagined seems to be the important variable here. This outcome certainly argues against the signal value hypothesis derived from recent studies. That is, repeated instructions to imagine the tone decreased rather than increased the response-evoking potential of that stimulus.

I n v o k i g S okolov's conceptualization, each time $S$ imagined a tone it served to prime the neuronal model of that tone. Subsequent encounters with the real stimulus failed to produce strong orienting because the partially formed model was already functioning to inhibit responding and real tone trials rapidly refined the model. By contrast, the rough neuronal model formed by imagining the visual stimulus (Group IL) failed to generalize to the auditory modality. Hence, performance in this group was not different from that of the Ss who had no opportunity to form any sort of neuronal model (Group NS). It appears that there is considerable justification for incorporating the "real-imaginary" dimension into any comprehensive account of the OR.

A somewhat different interpretation of these results contends that the procedures employed allow Ss to form expectancies or hypotheses concerning impending events. The group which imagined lights, therefore, might come to expect real lights later in the experiment. The greater responding by this group would then reflect the "disconfirmation" of such an expectancy. There are two arguments against this position. First, it is not at all clear that Ss who imagine lights will expect to get real lights or real tones, or anything for that matter, later on. The only basis for assuming this is the casual observation that many college Ss believe that psychological experiments involve some form of chicanery, and any of the above might qualify as such.

Second, Ss who imagined lights were not significantly different from Ss who received no stimulation (they were slightly more responsive on the amplitude measure and slightly less responsive on the trials to criterion measure). The "disconfirmed expectancy" position should regard the operations performed on Group IL as a form of strong novelty (e.g., Furedy \& Scull, in press) as opposed to weak novelty operations in Group NS. One might then predict greater orienting in Group IL.

Irrespective of theoretical issues, these data raise some interesting questions about the causal factors in desensitization therapies which emiploy imagery procedures. Systematic desensitization therapy considers relaxation training as the essential ingredient in the attenuation of fear responses to some stimulus. 
When imagery is employed, the assumption is that repeatedly imagining graded fear-eliciting situations concurrent with practiced relaxation behaviors results in establishment of a relaxation response which is incompatible with, and thus suppresses, the fear response (Wolpe, 1958). Alternatively, Lader \& Mathews (1968) suggest that imagery trials function to accelerate habituation to the fear stimulus. Presumably, imagery trials render the stimulus nonnovel and thus less c a pable of evoking an attention-facilitating OR. Diminution of the OR then would decrease sensitivity and attentive behavior to the stimulus and thus create a necessary condition for further reduction in the intrusiveness of the stimulus through some extinction-like set of operations.

While the results of the present study do not provide a direct test of this hypothesis, they do demonstrate that prior imagination of a stimulus (albeit a neutral one here) facilitates habituation to the real event.
Accordingly, these results are consistent with the proposition that imaginal experience with an aversive stimulus at least serves to reduce the orienting component of the response evoked by that stimulus.

\section{REFERENCES}

COHEN, M. J., \& JOHNSON, H. J. Effects of intensity and signal value of stimuli on the orienting and defensive responses. Journal of Experimental Psychology, $1971,88,286-288$.

CORMAN, C. D. Stimulus generalization of habituation of the galvanic skin response. Journal of Experimental Psychology, $1967,74,236-240$

FUREDY, J. J., \& SCULL, J. Orienting reaction theory and an increase in the human GSR following stimulus change which is unpredictable but not contrary to prediction. Journal of Experimental Psychology, in press.

HARVEY, B. \& WICKENS, D. D. Effects of instructions on responsiveness to the CS and UCS in GSR conditioning. Journal of Experimental Psychology. $1971,87,137-140$

KOHLENBERG, R. J. Instructions to ignore a stimulus and the GSR. Psychonomic Science, 1970, 19, 220-221.

LADER, M. H., \& MATHEWS, A. M. A physiological model of phobic anxiety and desensitization. Behavior Research \& Therapy, 1968, 6, 411-421.

MALTZMAN, I., \& RASKIN, D. Effects of individual differences on the orienting reflex. Journal of Experimental Research in Personality, 1965, 1, 1-16.

SOKOLOV, Ye. N. Perception and the condilioned reflex. New York: Pergamon Press, 1963.

UNGER, S. M. Habituation of the vasoconstrictive orienting reaction. Journal of Experimental Psychology. 1964, 67, 11-18.

WOLPE, J. Psychotherapy by reciprocal inhibition. Stanford: Stanford University Press. 1958.

WOLPE. J.. \& LAZARUS. A. A. Behavior therapy techniques. New York: Pergamon Press. 1966.

YAREMKO, R. M. Effects of direction and amount of change in stimulus intensity on magnitude of the orienting reflex and frequency of signal detection. Unpublished PhD dissertation, Ohio University, 1969 .

Y AREMKO, R. M. Reply to Ely. Psychonomic Science, 1971, 23, 414-415.

YAREMKO, R. M BLAIR, M. W., \& LECKART, B. T. The orienting reflex to changes in a conceptual stimulus dimension. Psychonomic Science. 1970. $21,115.116$

ZIMNY G, H, PAWLICK, G, F \& SAUR. D. P. Effects of stimulus order and novelty on orienting responses. Psychophysiology, 1969,6, 166-173.

ZIMNY, G. H. \& SCHWABE, L. M. Stimulus change and habituation of the orienting reflex. Psychophysiology, 1965 , 2, 103-115. 